\title{
Effects of imidazolium- and ammonium-based ionic liquids on clay swelling: experimental and simulation approach
}

\author{
Md Tauhidur Rahman ${ }^{1,2} \cdot$ Berihun Mamo Negash $^{1,2}$ (D) David Kwaku Danso ${ }^{1,2} \cdot$ Alamin Idris $^{3}$. \\ Ahmed Abdulla Elryes ${ }^{1} \cdot$ Ibrahim Adamu Umar ${ }^{1,2}$
}

Received: 21 September 2021 / Accepted: 27 November 2021 / Published online: 20 December 2021

(c) The Author(s) 2021

\begin{abstract}
Water-based fracturing fluids without an inhibitor promote clay swelling, which eventually creates wellbore instability. Several ionic liquids (ILs) have been studied as swelling inhibitors in recent years. The cations of the ILs are crucial to the inhibitory mechanisms that take place during hydraulic fracturing. Individual studies were carried out on several ILs with various cations, with the most frequently found being ammonium and imidazolium cations. As a result, the goal of this study is to compare these two cations to find an effective swelling inhibitor. A comparison and evaluation of the clay swelling inhibitory properties of tetramethylammonium chloride (TMACl) and 1-ethyl-3-methylimidazolium chloride (EMIMCl) were conducted in this work. Their results were also compared to a conventional inhibitor, potassium chloride ( $\mathrm{KCl})$, to see which performed better. The linear swelling test and the rheology test were used to determine the inhibitory performance of these compounds. Zeta potential measurements, Fourier-transform infrared spectroscopy, and contact angle measurements were carried out to experimentally explain the inhibitory mechanisms. In addition, the COSMO-RS simulation was conducted to explain the inhibitory processes and provide support for the experimental findings. The findings of the linear swelling test revealed that the swelling was reduced by $23.40 \%$ and $15.66 \%$, respectively, after the application of TMACl and EMIMCl. The adsorption of ILs on the negatively charged clay surfaces, neutralizing the charges, as well as the lowering of the surface hydrophilicity, aided in the improvement of the swelling inhibition performance.
\end{abstract}

Keywords Hydraulic fracturing fluids · Clay stabilizer · Shale hydration and swelling inhibition · Swelling inhibition mechanisms $\cdot$ COSMO-RS simulation

\section{Abbreviations}

BT

DIW

EMIMCl

FF

FT-IR

IL

(SH)in water
Bentonite

Deionized water

1-Ethyl-3-methylimidazolium chloride

Fracturing fluid

Fourier-transform infrared spectroscopy

Ionic liquid

Swelling height in water
(SH)in inhibitor

SIE

(SP)in water

(SP)in inhibitor

TMACl

Wt.

XRD
Swelling height in inhibitor's solution

Swelling inhibition efficiency

Swelling percentage in water

Swelling percentage in inhibitor's

solution

Tetramethylammonium chloride

Weight

X-ray diffraction
Berihun Mamo Negash

bmamo.negash@utp.edu.my

1 Department of Petroleum Engineering, Universiti Teknologi PETRONAS, 32610 Bandar Seri Iskandar, Perak Darul Ridzuan, Malaysia

2 Shale Gas Research Group (SGRG), Universiti Teknologi PETRONAS, 32610 Bandar Seri Iskandar, Perak Darul Ridzuan, Malaysia

3 Department of Engineering and Chemical Sciences, Karlstad University, 65188 Karlstad, Sweden

\section{Introduction}

The exploration and development of unconventional sources have received a lot of interest due to the rising energy demand and the depletion of conventional reserves. Low porosity, ultralow reservoir permeability, poor connectivity, non-Darcy flow, and high total organic content are the characteristics of unconventional reservoirs (Hurnaus and Plank 2015; Holditch and Madani 2010; Jin et al. 2019). Shale 
gas, shale oil, tight oil and gas, oil sands, coal bed methane, and gas hydrates are examples of unconventional reservoirs. Shale gas is a key energy source among these unconventional resources due to its large reserve volume. Shales are sedimentary rocks made up of clay minerals (smectite, illite, kaolinite, chlorite, and vermiculite), as well as other minerals like quartz, calcite, and feldspar (Lyu et al. 2015). The permeability of these reservoirs is extremely low $\left(10^{-12}\right.$ to $10^{-6} \mu^{2}$ ) (Liu et al. 2018). Due to the exceptional geophysical properties, the production of oil and gas from shale is not similar to that from conventional sources. Fortunately, with the advancement of technologies such as horizontal drilling and fracturing, the industry is shifting toward shale hydrocarbon production (Danso et al. 2020, 2021; Miah et al. 2018; Fujian et al. 2019; Biswas et al. 2020, 2021).

Fracturing involves the high-pressure injection of specially designed fracking fluids to create fractures in the formation (Joshi 1991). It improves the rate at which fluids are recovered from low permeable reservoirs. The fracturing fluids play a vital role during the fracturing process in the shale formation. There are different types of fracturing fluids such as oil-based fluids, foam-based fluids, and water-based fluids. Oil-based fluids are considered efficient fracturing fluids due to their superior lubricity, resistance to swelling, borehole stability, high-temperature resistance, and corrosion inhibitory properties (Villada et al. 2017). However, due to the high initial cost, environmental hazards, operational safety, and disposal, the use of oil-based fluids during drilling and fracturing operations has been limited. Foam-based fluids contain less water and have a high apparent viscosity, which allows for good proppant transportation and reduces formation damage. The disadvantages of foam-based fracturing fluids include low hydrostatic pressure and instability at higher temperatures and pressures (Yekeen et al. 2018; Gupta and Hlidek 2010; Wanniarachchi et al. 2015; Gandossi 2013). Water-based fracturing fluids can cause more fracture networks. Also, water is readily available and inexpensive (Gu and Mohanty 2014). However, when employing water-based fluids, the water-sensitive formation may encounter challenges such as hydration, swelling, and dispersion (Xu et al. 2018). The prevalent operational problems encountered in fracturing unconventional shale reservoirs using water-based fluids are mostly triggered by clay swelling. The severity of clay swelling can limit the wellbore diameter, causing stress distribution around the borehole to change, lowering the mechanical shale strength of the formation, causing borehole instability, and ultimately leading to reduced production (Xu et al. 2018, 2019; Guancheng et al. 2016). Mitigating the swelling of the clay minerals during the fracturing of shale formations is therefore crucial in ensuring a smooth fracturing operation.

Over the last five decades, several conventional and non-conventional inhibitors have been incorporated with water-based fluids to tackle the above-mentioned issues (Muhammed et al. 2021). Some of the conventional additives are inorganic salts, surfactants, polymeric, and aminebased inhibitors. Inorganic salts such as $\mathrm{KCl}, \mathrm{NaCl}, \mathrm{CaCl} 2$, and $\mathrm{NH} 4 \mathrm{Cl}$ have been shown to be effective in combating hydration and swelling shale formations at concentrations ranging from 2-20 wt\% (O'Brien and Chenevert 1973; AlMubarak et al. 2015; Gholami et al. 2018). Several researchers reported that inorganic salts may cause flocculation of fracturing fluids, which are incompatible with the fracturing fluids at higher concentrations and are harmful to the marine environment (Akhtarmanesh et al. 2013; Patel et al. 2007; Sehly et al. 2015; Quainoo et al. 2020; Zhong et al. 2011). On the other hand, the application of surfactants, polymeric, and amine-based inhibitors is limited due to their dependency on temperature and concentration, along with their lower inhibitive performance (Barati and Liang 2014).

Recent approaches are focusing on non-conventional inhibitors such as nanoparticles (Lara et al. 2017; Saleh and Ibrahim 2019; Yekeen et al. 2019), saccharides and their derivatives (Ma et al. 2019; Ismail and Ann 2009), bio-surfactants (Aggrey et al. 2019), and ionic liquids (ILs) (Rahman et al. 2020a, 2021). ILs are liquid organic salts composing of anions and cations along with substituents attached to the cation (Berry et al. 2008; Bubalo et al. 2014). These segments of the ILs have distinguished effects on clay swelling inhibition mechanisms. Ahmed Khan et al. (2020) studied the effects of halogen group anions and reported that there is negligible difference in their inhibition performances due to different halides (Ahmed Khan et al. 2020). The reason behind these similar inhibition performances is that these anions possess almost similar types of molecular properties. Rahman et al. (2021) investigated the effects of polyatomic anions on clay swelling inhibition and discovered that less electronegative polyatomic anions perform better (Rahman et al. 2021). Yang et al. (2019) investigated the effects of the alkyl side chain attached to the imidazolium cation and suggested that a short alkyl chain exhibited better inhibition performance (Yang et al. 2019). Several studies were done to evaluate the inhibition efficiency of imidazoliumand ammonium-based cations ( $\mathrm{Li}$ et al. 2019; Zhang et al. 2019; An et al. 2015). However, there is no comparative study between the performances of these cations. Moreover, their inhibition mechanisms are not well-explained. Therefore, this study focuses on investigating the performance of 1-ethyl-3-methylimidazolium chloride (EMIMCl) and tetramethylammonium chloride (TMACl) along with their inhibition mechanisms.

The linear swelling test and rheology test were conducted to evaluate the inhibitive performance of the inhibitors. The inhibition mechanisms were explained by the zeta potential measurement, FT-IR analysis, and contact angle 
measurement. Furthermore, COSMO-RS simulation studies were done to support the inhibition mechanisms explained by experimental methods.

\section{Materials and methods}

\section{Materials}

Tetramethylammonium chloride (TMACl), 1-ethyl-3-methylimidazolium chloride (EMIMCl), and potassium chloride $(\mathrm{KCl})$ were purchased from Avantis Laboratory Supply, Malaysia. In this study, the same anion $\left(\mathrm{Cl}^{-}\right)$and two distinct cations (ammonium and imidazolium) were used for swelling investigation to compare the effects of the two different cations on swelling inhibition. The clay sample used in the experiments was purchased SCOMI Oiltools. The mineralogy of the bentonite powder was studied using $\mathrm{X}$-ray diffraction (XRD) analysis. The bentonite powder was characterized by an $\mathrm{X}^{\prime} \mathrm{Pert}^{3}$ Powder X-ray diffractometer, and the X-ray scans were analyzed by the Highscore (plus) software (PANalytical). The mineralogical composition of the bentonite is given in Table 1 .

Montmorillonite is comprised of an octahedral sheet sandwiched between two tetrahedral sheets (Uddin 2018). They have a predisposition to swell because of this structural feature. As a result, the bentonite powder, which is primarily constituted of montmorillonite, was chosen for the experiments in this study. The physiochemical properties of the chemicals utilized in this study are given in Table 2 .

\section{Experimental studies}

\section{Linear swelling test}

For the linear swelling test, $13 \mathrm{~g}$ of dry bentonite powder was taken by using a digital weight measurement tool. Then, the measured bentonite powder was put into a wafer holder of the core wafer compactor. After that, the pressure valve attached to the respective pressure chamber was opened and another pressure valve was closed. Finally, 1450 psi pressure was applied with the hydraulic press and closed the pressure valve and held it for $60 \mathrm{~min}$. After $60 \mathrm{~min}$, the pressure valve was opened and waited until the pressure dropped to $0 \mathrm{psi}$, and then cylindrical shaped wafer was removed from the pressure chamber. The initial length and diameter of the wafer were measured by a digital caliper.

Figure 1 shows the schematic diagram of the linear swell meter used for this study. After measuring the length and diameter, the compacted bentonite wafer was placed into an automated dual-core HPHT linear swell meter (M46000). Before putting the wafer into the swelling chamber, the swell meter was calibrated with three standard wafers of different lengths. To check the deviation caused by this equipment, three runs using distilled water were performed repeatedly. The variation in results between these three runs was negligible. As a result, no repetitions for the other solutions were performed. A solution was prepared using water and a 2 wt.\% inhibitor ( $\mathrm{KCl} / \mathrm{TMACl} / \mathrm{EMIMCl})$ to check the inhibition performance of the ILs. Also, a fracturing fluid (FF) was prepared by adding $0.40 \mathrm{wt} . \%$ of guar gum, 0.20 wt. $\%$ of potassium carbonate, $0.10 \mathrm{wt} . \%$ of borate, $0.20 \mathrm{wt} . \%$ of HPAM, 2 wt.\% inhibitor, and water to check the compatibility of the ILs with FF. $75 \mathrm{ml}$ of FF or water-inhibitor solution was put into the swelling cell, and the swelling phenomenon was monitored for $24 \mathrm{~h}$ under $1000 \mathrm{psi}$ pressure and room temperature. The swelling heights and percentages were recorded by a data acquisition software which was connected to a computer. The swelling percentage was calculated through the software utilizing the following equation:

Swelling rate $=\frac{\text { Linear height at different time }- \text { Initial height }}{\text { Initial height }}$

$$
\times 100 \%
$$

Table 1 Mineralogical composition of the bentonite powder used in this study

\begin{tabular}{llll}
\hline Sample & Mineral & Composition & Interlayer space \\
\hline Bentonite & Montmorillonite $\left(\mathrm{Si}_{7.80} \mathrm{Al}_{1.72} \mathrm{Cs}_{0.16} \mathrm{Fe}_{0.20} \mathrm{Mg}_{0.28} \mathrm{O}_{20}\right)$ & $100 \mathrm{wt} \%$ & $12.17 \AA$ \\
\hline
\end{tabular}

Table 2 Physiochemical properties of the chemicals that were used in this study

\begin{tabular}{lllllll}
\hline Chemical Name & Chemical Formula & MW $(\mathrm{g} / \mathrm{mol})$ & Purity & Cation & Anion & Source \\
\hline Water & $\mathrm{H}_{2} \mathrm{O}$ & 18.02 & $\mathrm{NA}$ & $\mathrm{NA}$ & $\mathrm{NA}$ & NA \\
Potassium chloride & $\mathrm{KCl}$ & 74.55 & $\mathrm{AG}$ & $\mathrm{K}^{+}$ & $\mathrm{Cl}^{-}$ & Avantis laboratory supply, Malaysia \\
EMIMCl & $\mathrm{C}_{6} \mathrm{H}_{11} \mathrm{ClN}_{2}$ & 146.62 & $\geq 95.0 \%$ & $\mathrm{C}_{6} \mathrm{H}_{11} \mathrm{~N}_{2}^{+}$ & $\mathrm{Cl}^{-}$ & Avantis laboratory supply, Malaysia \\
TMACl & $\mathrm{C}_{4} \mathrm{H}_{12} \mathrm{ClN}$ & 109.60 & $\geq 98.0 \%$ & $\mathrm{C}_{4} \mathrm{H}_{12} \mathrm{~N}^{+}$ & $\mathrm{Cl}^{-}$ & Avantis laboratory supply, Malaysia \\
\hline
\end{tabular}

$N A$ Not applicable, $A G$ Analytical grade 


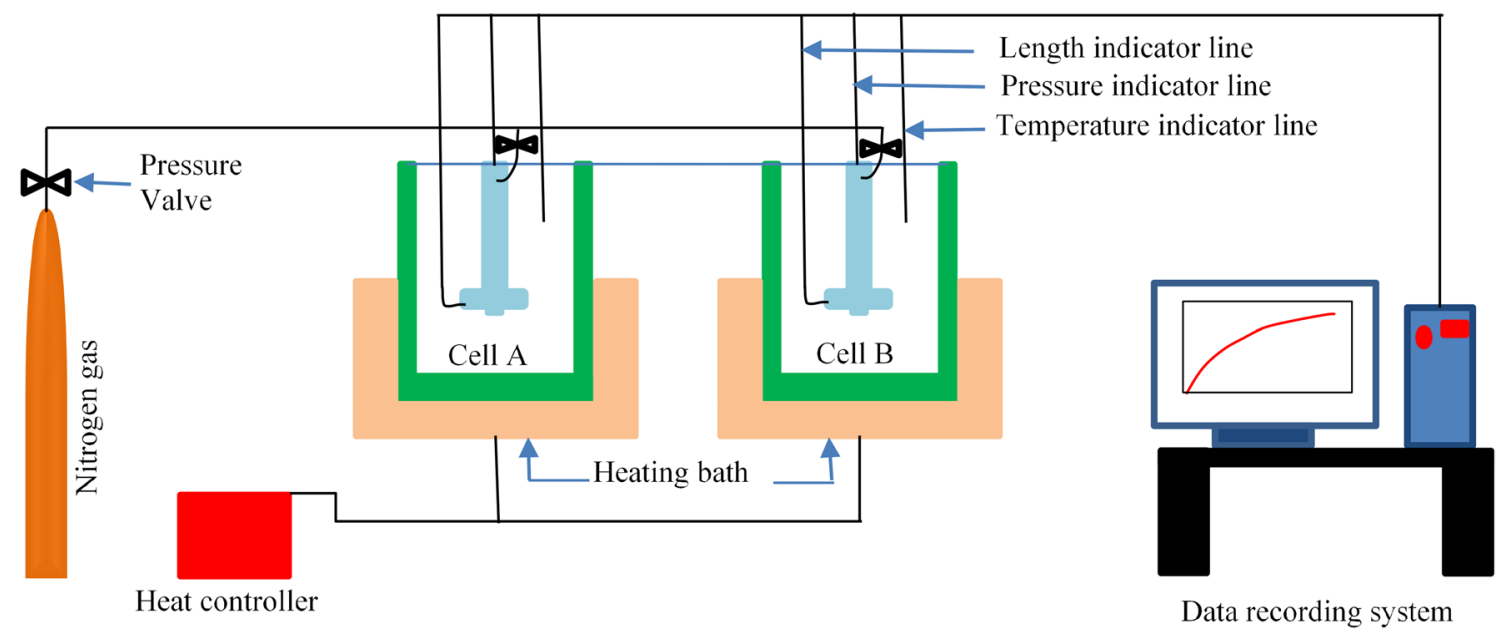

Fig. 1 Schematic diagram of the linear swell meter used for this study

Furthermore, to compare the swelling inhibition efficiencies of different ILs, the following equation was utilized:

elling inhibition efficiency $=\frac{S_{w}-S_{i}}{S_{w}} \times 100 \%$

ere $S_{w}$. is the swelling height or percentage in water, and $S_{i}$ is the swelling height or percentage in inhibitor's solutions.

\section{Rheology test}

The rheology of numerous bentonite suspensions was investigated in this study utilizing a high-precision Discovery Hybrid Rheometer (DHR-1) with a cup and bob measuring geometry with a gap of $5917 \mu \mathrm{m}$. The sample suspensions were prepared by mixing $4 \mathrm{~g}$ of bentonite powder, $2 \mathrm{~g}$ of inhibitor (KCl/TMACl/EMIMCl), and $94 \mathrm{~g}$ water. The mixers were stirred by using a fann five-spindle multi-mixer for $30 \mathrm{~min}$. The rheometer was set at $25^{\circ} \mathrm{C}$, and several conditioning steps (soaking time of $30 \mathrm{~s}$ and equilibration of $60 \mathrm{~s}$ ) were performed on the samples to bring them into thermal equilibrium. A steady flow sweep was applied with a varying shear rate from 0.01 to $1000 \mathrm{~s}^{-1}$. The tests were conducted at $25{ }^{\circ} \mathrm{C}$ and $75^{\circ} \mathrm{C}$ to measure the viscosity of the bentonite suspensions. Finally, genetic algorithms (GA) were employed to optimize three parameters of the Herschel-Bulkley flow model: yield stress, flow consistency index, and flow behavior index.

\section{Zeta potential measurement}

The samples for zeta potential measurements were prepared by adding 0.2 wt. $\%$ bentonite powder, 2 wt.\% inhibitor, and $97.80 \mathrm{wt} . \%$ water. At first, $0.2 \mathrm{~g}$ bentonite powder was measured by a digital weight balance, and $97.80 \mathrm{ml}$ water was measured by a test tube. Then, the water and bentonite powder were mixed and magnetically stirred for $24 \mathrm{~h}$. After that, $19.6 \mathrm{ml}$ of the water-bentonite solution was taken and mixed with $0.4 \mathrm{~g}$ of inhibitor (KCl/TMACl/EMIMCl). The water-bentonite-inhibitor solutions were again stirred for $16 \mathrm{~h}$ by a magnetic stirrer. Finally, the zeta potential value of the bentonite-water and bentonite-water-inhibitor solutions was measured using a zeta potential analyzer (zetasizer Nano ZSP).

\section{FT-IR analysis}

At first, $10 \mathrm{~g}$ of dry bentonite powder was measured by a digital weight balance. Then, the measured sample was put into the pressure chamber of the compactor and compacted under 1000 psi pressure for $30 \mathrm{~min}$. After the compaction, the bentonite wafers were immersed in water and inhibitor solutions and kept for $24 \mathrm{~h}$. Then, the wet bentonite wafers are taken out of the solutions and dried in an oven at $80{ }^{\circ} \mathrm{C}$ for approximately $16 \mathrm{~h}$. After that, the dried bentonite was crushed into fine powder by pestle and mortar. The IR spectral of the powdered bentonite modified with inhibitors was measured by a PerkinElmer Spectrum 400 spectrometer. The experiment was conducted at room temperature within the range of 4000 to $400 \mathrm{~cm}^{-1}$.

\section{Contact angle measurement}

The contact angle measurement was conducted to check the clay's wettability changes which can determine the inhibition mechanisms of the inhibitors. The contact angles for this research were measured by a KRUSS Drop Shape Analyzer (DSA25). At first, $10 \mathrm{~g}$ dry bentonite powder was measured by a digital weight balance. Then, the bentonite sample was 
placed into the pressure chamber and compacted for $30 \mathrm{~min}$ at a pressure of $1000 \mathrm{psi}$. Then for $48 \mathrm{~h}$, the bentonite wafers were immersed in water and inhibitor solutions. The wet bentonite wafer was removed from the solutions and dried at room temperature for approximately $72 \mathrm{~h}$. To make the surfaces smooth, the wafers were again put into the pressure chamber and compacted for $5 \mathrm{~min}$. Upon smoothing, the bentonite wafer was placed on the stage between the camera and light source. Then, the stage's position was fixed by adjusting its horizontal and vertical positions. Once the wafer's position is fixed, then the intensity of the light is adjusted. After completing all the settings, a small drop of water placed on the clay wafer's surface and the value of contact angles along with their images were recorded in the data acquisition unit.

\section{COSMO-RS simulation}

Theoretical studies or molecular dynamics simulations are required to overcome the challenges raised by experimental studies such as cost and time (Bains et al. 2001; Al-Arfaj et al. 2015). The swelling inhibition mechanisms of the inhibitors can be explained by zeta potential measurement, FT-IR analysis, and contact angle measurements. However, theoretical studies such as the COSMO-RS simulation study can also support the experimental methods used to explain the inhibition mechanisms. In this study, the computer simulation COSMO-RS (COSMOtherm Version 19.0.0 (Revision 5259)) is utilized to analyze the mechanisms working behind the swelling inhibition processes. This simulation software takes less time and is more effective at predicting the interactions between the water molecules and ILs. Herein, the sigma surfaces and surface area (chain length) of the studied ILs and the water molecules were determined by the COSMO-RS simulation software. The color of sigma surfaces helps to describe the charge distribution of a chemical in its structure. Moreover, the hydrogen bond energy produced between the water molecules and ILs is studied in this work.

3. Results and discussion

\section{Linear swelling test}

By comparing the swelling caused by water and ILs, the swelling percentage of the bentonite wafer with and without an inhibitor was determined. Furthermore, these results were compared with the conventional inhibitor KCl. Cations play a vital role during swelling inhibition processes. Herein, the impacts of imidazolium and ammonium cations were studied and presented. Figure 2 and Table 3 show that

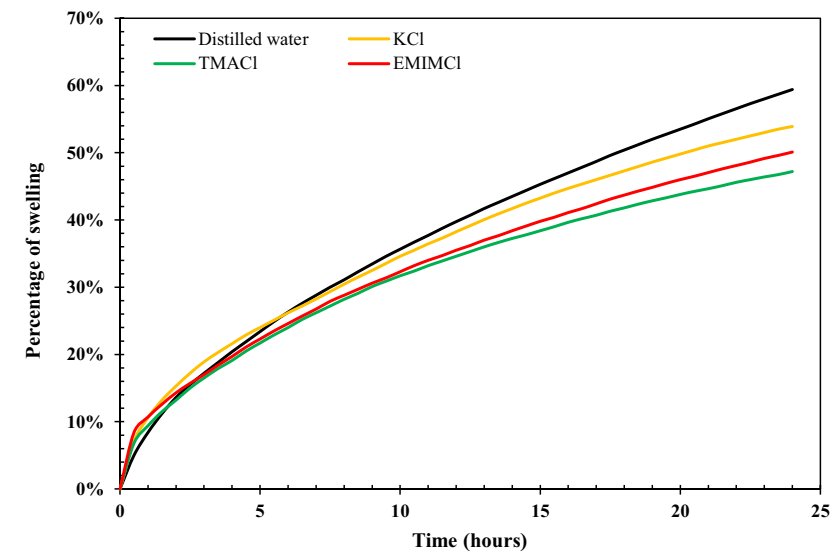

Fig. 2 Swelling percentage for distilled water, $\mathrm{KCl}, \mathrm{TMACl}$, and EMIMCl for $24 \mathrm{~h}$

TMACl depicted superior swelling inhibition performance to EMIMCl from the very beginning.

Figure 2 depicts the swelling rate of bentonite wafer with distilled water, $\mathrm{KCl}, \mathrm{TMACl}$, and EMIMCl through $24 \mathrm{~h}$. The bentonite wafer swelled to $59.40 \%$ of its original size in water, indicating a significant hydration and swelling tendency. After adding $2 \mathrm{wt} . \% \mathrm{KCl}$, the swelling rate was reduced to $53.90 \%$. This reduction indicates the swelling inhibition efficacy of the conventional inhibitor, $\mathrm{KCl}$. The swelling curve for $\mathrm{KCl}$ shows that up to $6 \mathrm{~h}$, it promotes the swelling compared to water. This happens due to the slower penetration rate of the potassium ions and the penetration of clay minerals by the massive water volume during the cationic penetration and replacement processes (O'Brien and Chenevert 1973; Agag and Akelah 2011).

When the imidazolium- and ammonium-based ILs were introduced, the bentonite wafer swelled less than when only water was supplied. The swelling reduction occurred because of the ILs adhering to the bentonite surface via electrostatic attraction. This adsorption of the positively charged groups of ILs decreased the bentonite's negative surface charge, compressing the double electric layers. Some of the adsorbed IL molecules may be intercalated into the vacuum of the bentonite interlayer, where they may eject some water molecules. It decreased bentonite's water adsorption capability, resulting in reduced hydration and swelling.

Table 3 indicates the swelling rate for water, $\mathrm{KCl}$, EMIMCl, and TMACl at $1 \mathrm{~h}, 6 \mathrm{~h}, 12 \mathrm{~h}$, and $24 \mathrm{~h}$. At the beginning (after $1 \mathrm{~h}$ ), the swelling rates were $10.70 \%$ and $6.20 \%$, and after $24 \mathrm{~h}$, the rates were $50.10 \%$ and $45.50 \%$ for EMIMCl and TMACl, respectively. TMACl showed a lower swelling rate than EMIMCl throughout the whole $24 \mathrm{~h}$. The tetramethylammonium cations can easily and strongly adsorb onto the bentonite clay particles through electrostatic attraction forces and hydrogen bonding. This

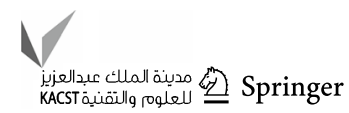


Table 3 Percentage of swelling after 1 h., 6 h., 12 h., and $24 \mathrm{~h}$. for different cations

\begin{tabular}{lclll}
\hline Experimental fluid system & Swelling\% at 1 h & Swelling\% at 6 h & Swelling\% at 12 h & Swelling\% at 24 h \\
\hline Water (100 wt.\%) & $8.40 \%$ & $26.30 \%$ & $39.75 \%$ & $59.40 \%$ \\
Water (98 wt.\%)+ KCl (2 wt.\%) & $10.60 \%$ & $26.20 \%$ & $38.25 \%$ & $53.90 \%$ \\
Water (98 wt.\%)+ EMIMCl (2 wt.\%) & $10.70 \%$ & $24.60 \%$ & $35.50 \%$ & $50.10 \%$ \\
Water (98 wt.\%)+ TMACl (2 wt.\%) & $6.20 \%$ & $21.30 \%$ & $32.60 \%$ & $45.50 \%$ \\
\hline
\end{tabular}

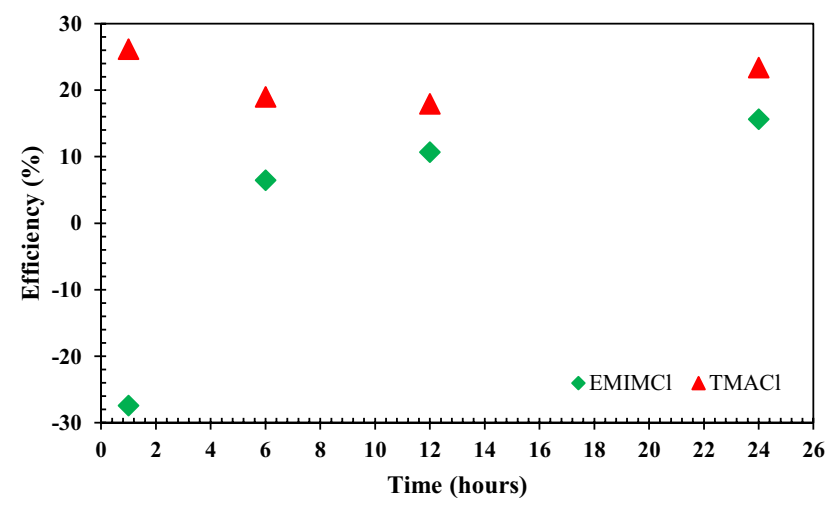

Fig. 3 Swelling inhibition efficiency for EMIMCl and TMACl at $1 \mathrm{~h}$., $6 \mathrm{~h} ., 12 \mathrm{~h}$., and $24 \mathrm{~h}$

helped to reduce the surface negative charge and double electric layers, hence reducing the swelling.

Figure 3 shows the swelling inhibition efficiency for EMIMCl and TMACl at 1 h., 6 h., 12 h., and 24 h. At the beginning (at $1 \mathrm{~h}$.), the swelling inhibition efficiency of TMACl was $26.19 \%$ and $-27.38 \%$ was for EMIMCl. At the beginning, TMACl showed higher swelling inhibition efficiency, which indicated the faster penetration rate of tetramethylammonium ions than the imidazolium ions. However, with time (especially up to $12 \mathrm{~h}$ ), the inhibition efficiency of EMIMCl was increased. On the other hand, the inhibition efficiency for TMACl was following a decreasing trend but still maintained a higher inhibition efficiency than EMIMCl. After $12 \mathrm{~h}$, the inhibition efficiency for TMACl again followed an increasing trend and maintained superior inhibition efficiency until the end of this experiment.

Figure 4 represents the percentage of swelling for FF, $\mathrm{FF}+\mathrm{KCl}, \mathrm{FF}+\mathrm{EMIMCl}$, and $\mathrm{FF}+\mathrm{TMACl}$ mixtures. The rate of swelling with $\mathrm{FF}$ after $24 \mathrm{~h}$ was $46.40 \%$, which was reduced to $43.20 \%, 38.60 \%$, and $35.20 \%$ after adding $\mathrm{KCl}$, EMIMCl, and TMACl, respectively, to the FF. TMACl retained its superior performance with $\mathrm{FF}$ in this case as well, which indicates the better compatibility of TMACl with FF. Both ILs (EMIMCl and TMACl) showed superior performance to $\mathrm{KCl}$ with the FF. These results indicate that the studied ILs are compatible with the fracturing fluids.

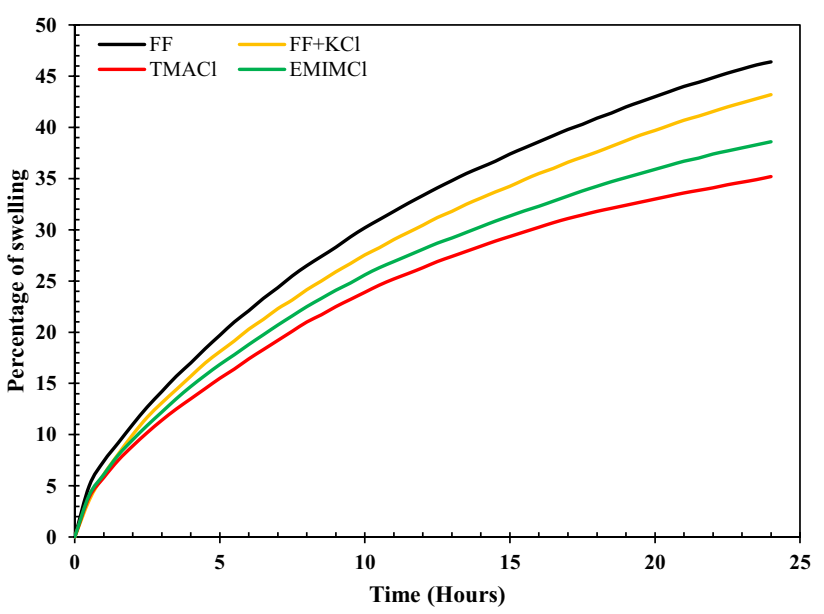

Fig. 4 Swelling percentage for $\mathrm{FF}, \mathrm{FF}+\mathrm{KCl}, \mathrm{FF}+\mathrm{EMIMCl}$, and $\mathrm{FF}+\mathrm{TMACl}$ for $24 \mathrm{~h}$

\section{Rheology test}

Herein, the rheological parameters of the bentonite-water, bentonite-water- $\mathrm{KCl}$, bentonite-water-EMIMCl, and bentonite-water-TMACl are briefly discussed. The rheological parameters of a drilling or fracturing fluid are investigated in order to determine the flow behavior (Wang et al. 2017). However, in this study, the rheological properties were utilized to assess the swelling inhibition ability of an inhibitor (Rahman et al. 2020b; Xuan et al. 2015). It is believed that the swelling and dispersion of clay minerals increases the viscosity and as a result, increases the yield stress value (Xiong et al. 2019; Aubry and Moan 1997; Rubbi et al. 2021). Hence, the viscosity and yield stress measurements can be used to evaluate the chemical's effectiveness in preventing swelling or dispersion. Higher inhibitory efficiency is indicated by a lower viscosity value for a given chemical.

The viscosity is shown in Fig. 5, and Table 4 summarizes the rheological properties of bentonite-water and bentonite-water-inhibitors containing various cations (calculated by the Herschel-Bulkley model). After integrating $\mathrm{KCl}$, EMIMCl, and TMACl into the bentonite-water suspensions, the viscosity and yield stress were lowered. The yield stresses for KCl-water-bentonite, EMIMCl-water-bentonite, 

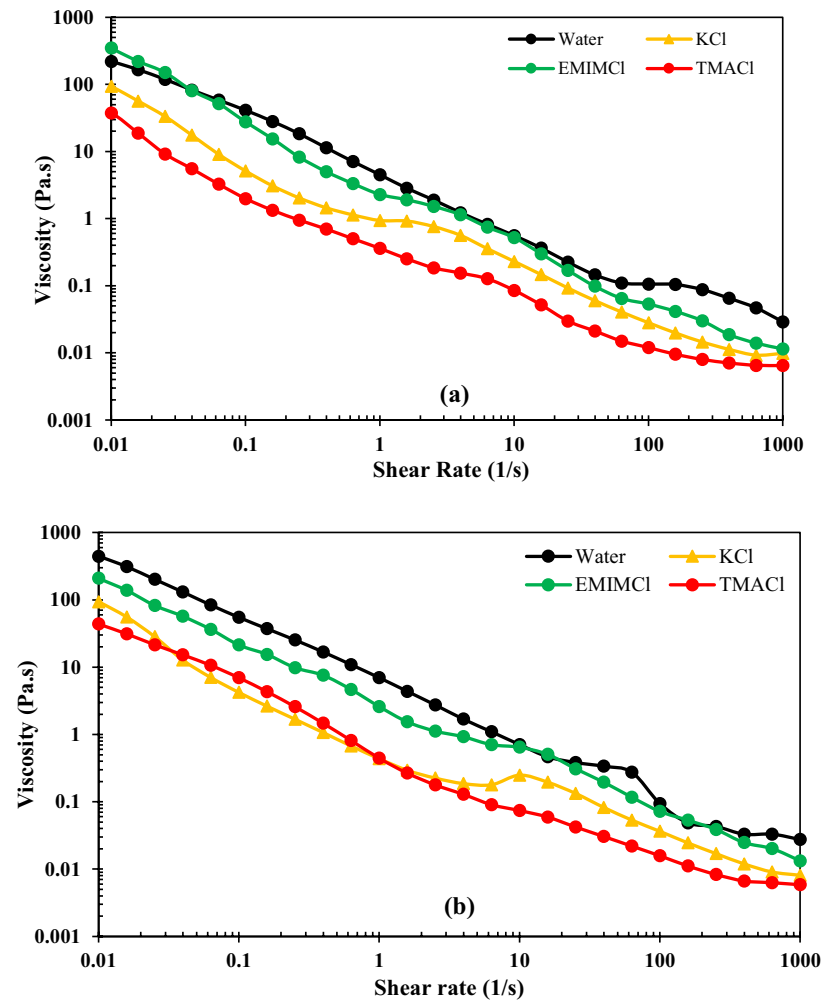

Fig. 5 Flow behavior of bentonite-water and bentonite-water-inhibitor (with different cations) suspensions; a viscosity vs shear rate at $25^{\circ} \mathrm{C}$ and $\mathbf{b}$ viscosity vs shear rate at $75^{\circ} \mathrm{C}$

Table 4 Rheological parameters of the bentonite-water and bentonitewater-inhibitors (with different cations) suspensions at $25{ }^{\circ} \mathrm{C}$ (calculated by Herschel-Bulkley model)

\begin{tabular}{llll}
\hline Inhibition system & $\begin{array}{l}\text { Yield } \\
\text { stress, YS } \\
(\mathrm{Pa})\end{array}$ & $\begin{array}{l}\text { Consistency } \\
\text { index, K (Pa. } \\
\left.\mathrm{s}^{\mathrm{n}}\right)\end{array}$ & Flow index, $\mathrm{n}$ \\
\hline Water+BT & 2.9443 & 0.0165 & 0.9798 \\
$\mathrm{KCl}+$ water+BT & 1.2665 & 0.0118 & 0.9475 \\
EMIMCl+water+BT & 2.9004 & 0.0157 & 0.9674 \\
TMACl+water+BT & 1.1656 & 0.0113 & 0.9406 \\
\hline
\end{tabular}

and TMACl-water-bentonite suspensions were 1.2665, 2.9004 , and $1.1656 \mathrm{~Pa}$, respectively. On the other side, the value was $2.9443 \mathrm{~Pa}$ for the water-bentonite suspension.

The reduction in the yield stress value supports the higher swelling inhibition efficiency of the inhibitors. As previously stated, lower yield stress values were obtained by controlling bentonite swelling and dispersion through neutralizing the surface negative charge and decreasing the repulsive force between two clay sheets. While the decreased yield stress and viscosity are advantageous for the swelling inhibition procedure, they might occasionally present problems for the proppant transportation facility. However, there is a good solution to this problem; prehydrated bentonite combined with fracturing fluids can demonstrate a high capacity for proppant transporting.

\section{Zeta potential measurement}

The zeta potential measurement is an important technique to explain the inhibition mechanisms. Herein, the effect of cations on the reduction in negative surface charges is briefly discussed.

Figure 6 represents the zeta potential value of bentonite-water and bentonite-water-inhibitor suspensions. The zeta potential of bentonite in water was $-33.53 \mathrm{mV}$, indicating a considerable colloidal system. These negative charges produce opposing forces between two layers of the clay minerals due to their repulsive nature. The repulsive force can cause the separation of two silicate layers, which can result in swelling of the clay minerals. However, after adding $\mathrm{KCl}$, $\mathrm{EMIMCl}$, and $\mathrm{TMACl}$, the zeta potential value changed to $-23.40,-14.30$, and $-9.90 \mathrm{mV}$, respectively. These zeta potential values indicated the demotion of the colloidal system after adding ILs and $\mathrm{KCl}$. Generally, a low zeta potential value reduces the repulsive forces between the clay layers and accelerates the agglomeration of bentonite particles. Agglomeration of clay mineral is favorable for swelling and dispersion inhibition.

Figure 7 depicts the negative surface charge reduction efficiency of $\mathrm{KCl}$ and ILs. The zeta potential reduction by $\mathrm{KCl}$, EMIMCl, and TMACl was $23.21,57.35$, and $70.47 \%$, respectively. All these inhibitors reduced the negative zeta

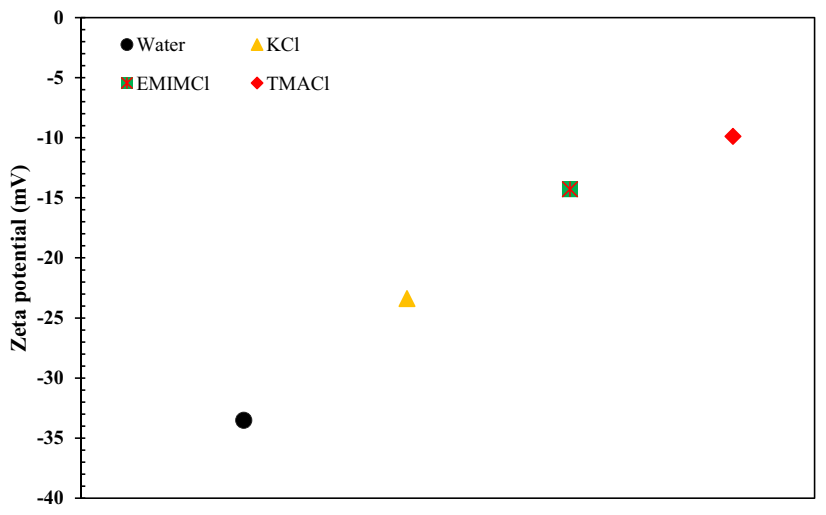

Fig. 6 Zeta potential values for bentonite-water and bentonite-waterinhibitor solutions 


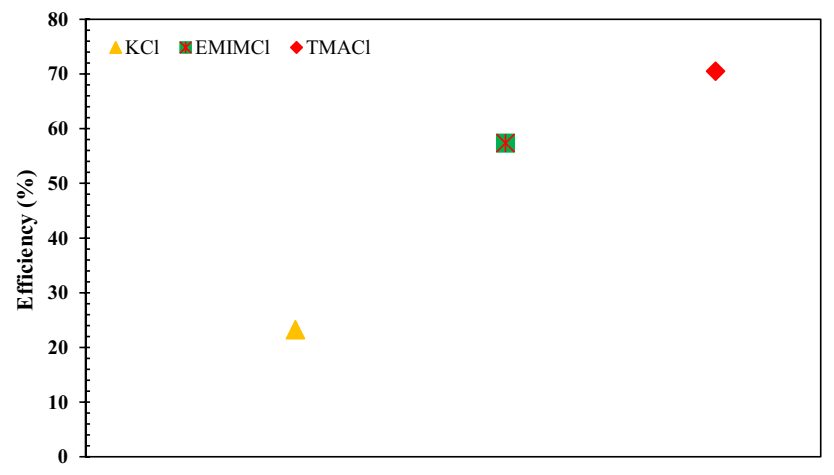

Fig. 7 Efficiency of various inhibitors in negative surface charge reduction

potential value by more than $20 \%$, indicating that they are effective inhibitors. So far, the ammonium cation has shown excellent efficiency compared to the imidazolium cation. Owing to four methyl chains attached to the cation, TMACl may help to reduce more negative charges than the imidazolium cation. Due to the high electrostatic attraction between the TMACl and bentonite particles, the TMACl readily adsorbs on the bentonite surface, resulting in the reduction in negative surface charge. Moreover, the four methyl chains of TMACl increase the hydrophobicity of the bentonite surface, which helped to decrease the negative zeta potential value.

\section{FT-IR analysis}

FT-IR analysis was conducted to further investigate the intercalation of ILs on the bentonite clay. This test helps to investigate the adsorption ability of the inhibitors on the clay surface. For the bentonite sample shown in Fig. 8, the spectrum reveals the typical characteristic absorption bands. The noticeable peak at $3621 \mathrm{~cm}^{-1}$ was assigned to the $\mathrm{O}-\mathrm{H}$ stretching vibration. A large absorption band at $3435 \mathrm{~cm}^{-1}$ was found to correspond to the physisorbed water in the galleries of bentonite, while the $\mathrm{H}-\mathrm{O}-\mathrm{H}$ deformation vibration of water molecules was found at $1641 \mathrm{~cm}^{-1}$. Moreover, a strong absorption band at $1036 \mathrm{~cm}^{-1}$ represented asymmetric stretching vibrations of $\mathrm{Si}-\mathrm{O}$ and 521 indicated the deformation band of Al-O-Si.

After the effective adsorption of these ILs on bentonite, all FT-IR spectra of bentonite-ILs hybrids exhibited additional absorption peaks at $2970 \mathrm{~cm}^{-1}$ and $2874 \mathrm{~cm}^{-1}$, which corresponded to the stretching vibration of the methyl groups. The presence of these two peaks proved the incorporation of ILs into the bentonite clay. For TMACl-bentonite composite, a significant peak was found at $1487 \mathrm{~cm}^{-1}$ which represents $\mathrm{N}-\mathrm{CH}_{3}$ bonds. This peak was absent in the spectra of bentonite, bentonite- $\mathrm{KCl}$, and bentonite-EMIMCl composites. Table 5 shows some of the significant bonds present in bentonite and inhibitor-bentonite composites.

Table 5 Significant bonds present in bentonite and inhibitor-bentonite composites

\begin{tabular}{llllll}
\hline Peak & Bond & BT & BT-KCl & BT-EMIMCl & BT-TMACl \\
\hline 521 & Al-O-Si (D) & present & present & present & present \\
1036 & Si-O (S) & present & present & present & present \\
1487 & N-CH & absent & absent & absent & present \\
1642 & H-O-H (D) & DP & DP & SP & SP \\
2874 & C-H (S) & absent & absent & weak & weak \\
2970 & C-H (S) & absent & absent & weak & weak \\
3621 & O-H (S) & present & present & present & present \\
\hline
\end{tabular}

Fig. 8 FT-IR spectra of bentonite, KCl-bentonite, EMIMClbentonite, and TMACl-bentonite composites

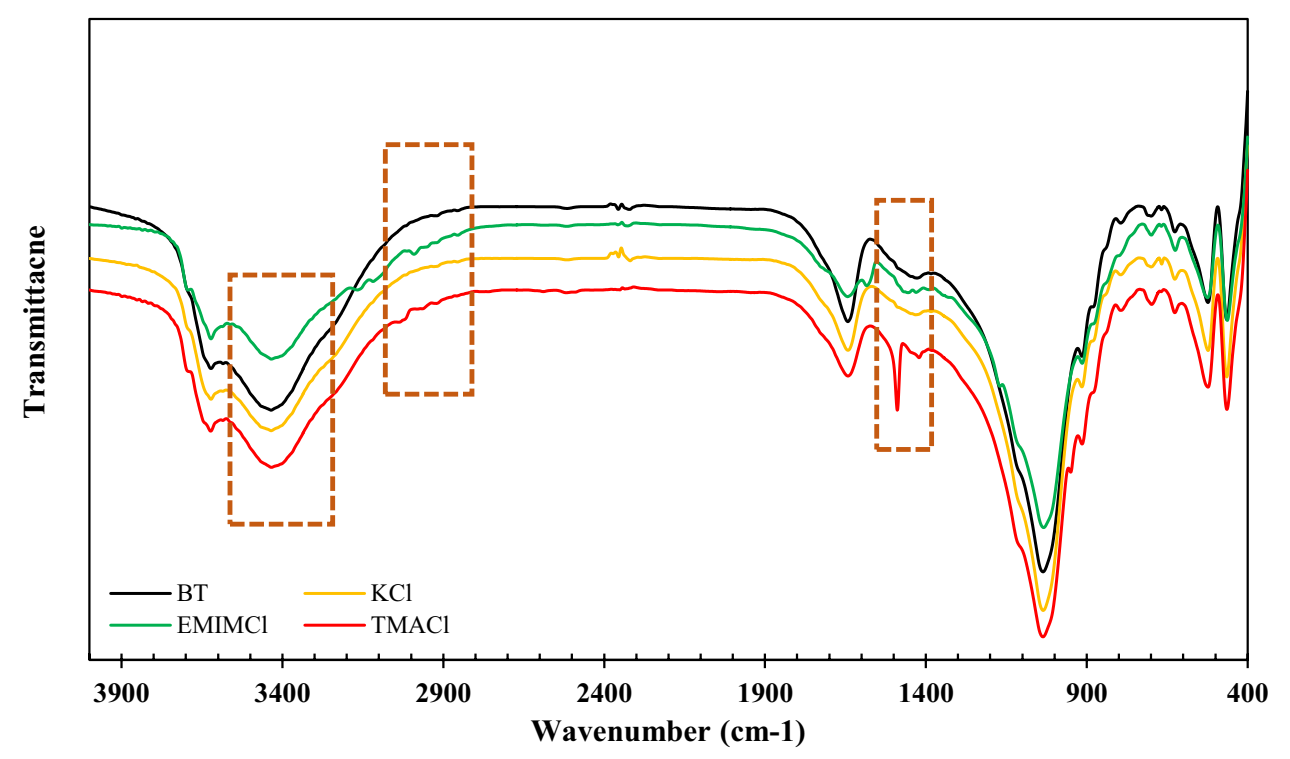




\section{Contact angle measurement}

The wettability of the shale surface is a vital factor in understanding and analyzing the swelling inhibition mechanisms. Contact angle calculation is a simple way to assess wettability changes on a surface. Herein, the effects of cations on contact angle are briefly discussed.

The contact angles between a water drop and a bentonite surface or a water drop and a bentonite surface treated with ILs are shown in Fig. 9. The average contact angles for the bentonite surface treated with TMACl and EMIMCl were $50.35^{\circ}$ and $47.4^{\circ}$, respectively. On the other side, the contact angle between water and pure bentonite was $31.45^{\circ}$, which indicated a hydrophilic state of the bentonite surface. The more hydrophilicity of the clay surface accelerates the attraction to water molecules, which promotes the hydration and swelling of the clay. However, after modifying the bentonite surface with TMACl and EMIMCl, the contact angle increased by $60.10 \%$ and $50.72 \%$, respectively. This increase in the contact angles indicated the reduction in hydrophilicity or the increase in hydrophobicity. Among these two ILs, TMACl showed better hydrophilicity reduction than EMIMCl. Therefore, it can be concluded that tetramethylammonium cations have more potential to alter the surface hydrophilicity.

\section{COSMO-RS simulation studies}

The COSMO-RS simulation studies were conducted to better explain the inhibition mechanisms and support the results obtained from experimental studies. In this study, sigma surfaces of the cations and anion of ILs and water, surface area of the studied chemicals, and hydrogen bond energies between water and ILs were investigated. All these properties have a direct relationship with the swelling inhibition mechanisms.

Figure 10 represents the sigma surfaces of water, tetramethylammonium cation, 1-ethyl-3-methylimidazolim cation, and chloride anion. The scale of interpretation shows that deep blue color indicates highly electropositive charge and deep red color indicates highly electronegative charge. When these colors gradually become faded, it means the electropositivity or electronegativity are decreasing. Most of the surface area of the tetramethylammonium cation is electropositive, with only a few minor areas that are highly electropositive and partially electropositive present. Specifically, when it comes to the 1-ethyl-3-methylimidazolium cation, the maximum area is partially electropositive, with only a few minor areas being highly electropositive and electropositive. Accordingly, the positive charge distribution on the tetramethylammonium cation is greater than the positive charge distribution on the 1-ethyl-3-methylimidazolium cation. This somewhat greater positive charge facilitates the adsorption of the tetramethylammonium cation on the clay surfaces, resulting in a reduction in more surface
Fig. 9 Contact angles between water drop and bentonite surface; $\mathbf{a}$ bentonite surface modified with TMACl, b bentonite surface modified with EMIM, and $\mathbf{c}$ pure bentonite
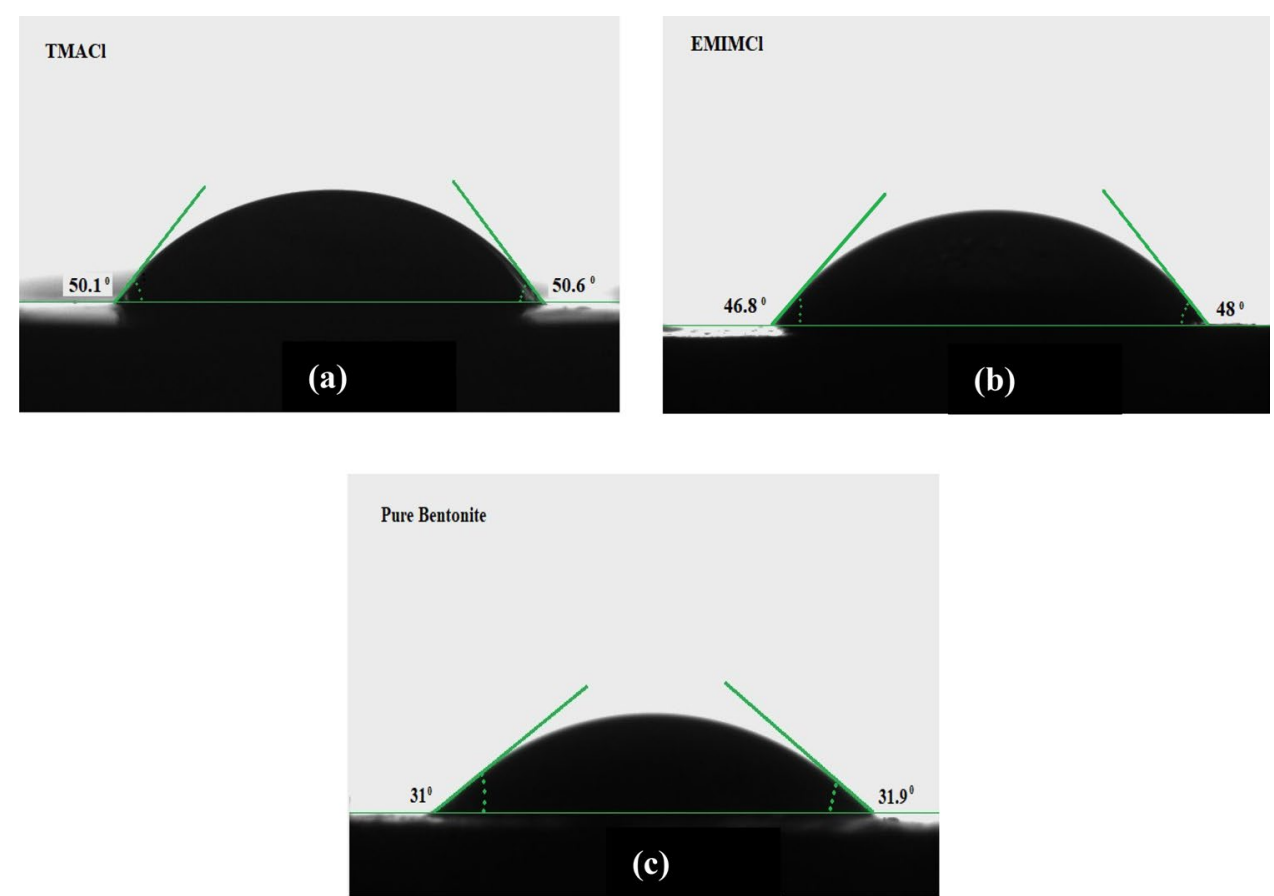


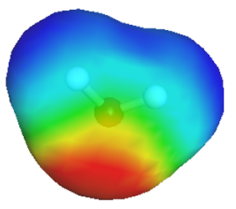

Water

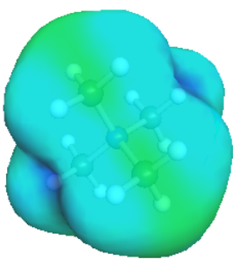

TMA cation

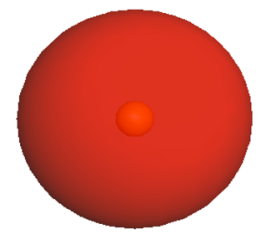

Chlorine anion

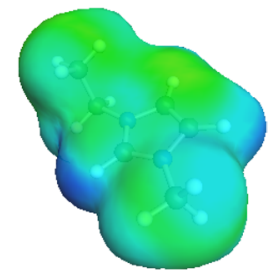

EMIM cation highly electronegative

electronegative

partially electronegative

partially electropositive

electropositive

highly electropositive

Scale for interpretation

Fig. 10 Sigma surfaces of the cations and anion of the studied inhibitors

negative charges. This reduction in surface charge eventually contributes to a reduction in clay swelling.

According to Table 6, the hydrogen bond energies produced by the interaction of water with EMIMCl and water with $\mathrm{TMACl}$ were $-26.07573 \mathrm{kcal} / \mathrm{mol}$ and $-25.65217 \mathrm{kcal} / \mathrm{mol}$, respectively. Instead of expressing negative numbers, the minus (-) sign represents the production of energy during the bond formation process in this case. This indicates that TMACl forms fewer hydrogen bonds with water molecules than EMIMCl, hence producing less hydrogen bond formation energy. Knowing that both of the ILs contain the same anion, it is reasonable to conclude that the difference in hydrogen bond energy between them is due to differences in the cations present. Whenever the tetramethylammonium cation enters the clay interlayer space, it draws a smaller number of water molecules, resulting in a reduction in swelling.

\section{Proposed role of cations in swelling inhibition}

Numerous chemicals were investigated as swelling inhibitors in order to smooth out the hydraulic fracturing process of the clay-rich shale formation. Each chemical has its own mode of anti-swelling action. For a few years, ILs have been studied for their potential as swelling inhibitors. However, their inhibition mechanisms are not well-understood. Hence, the possible inhibition mechanisms by cations are briefly discussed here. When IL enters the interlayer space, it quickly gets adsorbed on the clay surfaces through electrostatic attraction forces. The hydrogen bonds formed between the positive cations of IL and the silicate tetrahedron of clay particles intensify the adsorption process. The presence of more positive charge on the surface of the cations promotes the adsorption process. Being adsorbed on the clay surface, the cations neutralized the negative surface charges and suppressed the repulsive double electric layer (proved by the zeta potential value). The neutralization of negative charges reduced the hydrophilicity of clay surfaces (proved by the contact angle measurements); hence, they show less attraction to water molecules. Moreover, the coordination of hydrogen bonds and electrostatic attraction forces may expel water molecules from the interlayer spaces and fix the clay plates together. The alkyl chain attached to the cation core of the adsorbed ILs makes a hydrophobic shield and covers the clay surface, which also impedes the water ingress into the interlayer space. More alkyl chains attached to the cation facilitate more swelling inhibition. The higher positive charge on the surface of the tetramethylammonium cation, as well as the presence of more alkyl chains attached to it, contributed to its superior inhibitory performance when compared to the 1-ethyl-3-methylimidazolium cation.

Table 6 Studied parameters for different inhibitors generated by COSMO-RS computer simulation

\begin{tabular}{llllll}
\hline Inhibition system & Concentration & $E_{\mathrm{HB}}(\mathrm{kcal} / \mathrm{mol})$ & Surface area $\left(\mathrm{A}^{2}\right)$ & $\begin{array}{c}\text { Volume }\left(\mathrm{V}^{3}\right) \\
\begin{array}{l}\text { Efficiency } \\
\text { from exp. } \\
\text { study) }\end{array}\end{array}$ \\
\hline EMIMCl + water & EMIMCl (2\%) Water (98\%) & -26.07573 & 214.86408 & 191.88735 \\
TMACl + water & TMACl (2\%) Water (98\%) & -25.65217 & 180.56222 & 158.90884 & $23.40 \%$ \\
\hline
\end{tabular}




\section{Conclusion and recommendation}

The swelling of the ultralow permeability owned shale formation is caused as a result of geochemical interactions between water and clay minerals during hydraulic fracturing processes. This is extremely detrimental to effective shale gas extraction due to the formation damage and production constraints. Numerous additives, including organic salts, inorganic salts, surfactants, polymers, and amine derivatives, have been proposed as fracturing fluids to address this issue, but they all have significant downsides. Recent research has concentrated on ILs composed of a cationic component, an anionic component, and substituents attached to the cationic core. Each of these three components has a considerable effect on the suppression of clay swelling processes. So far, there is no significant comparative work on the impact of cations on clay swelling inhibition. Hence, this research examined the effects of ammonium and imidazolium cations on clay swelling inhibition, as well as the mechanisms underlying their inhibition. The following concluding statements are made in light of the experimental and COSMO-RS simulation investigations conducted on the two ILs as clay swelling inhibitors.

- Both ILs outperformed the traditional inhibitor $\mathrm{KCl}$ in terms of inhibition. As a result, IL may be a potential alternative to conventional inhibitors.

- Among the two cations evaluated with chloride anion in this research, ammonium-based IL (TMACl) outperformed imidazolium-based IL (EMIMCl).

- More positive charge on the cation's surface accelerates the adsorption process and reduces the negative surface charge of the clay mineral, resulting in less clay swelling.

- More alkyl chains attached to the cation improve inhibitory efficacy.

Based on the research conducted in this study, a few suggestions can improve the research scope in the future.

- In the simulation study of this work, only the interactions between ILs and water molecules were investigated. However, the interaction between the ILs and clay minerals requires further investigation.

- In this work, only two types of cations were studied. Some other cations (for example, phosphonium, piperidines, pyridiniums, pyrrolidines, sulfones, morpholines, guanidiniums, choline, oxazolium, triazolium, thiazolium, pyrazolium, $\mathrm{N}$-alkyl-isoquinolinium) need to be studied.
Acknowledgements The authors express their gratitude to Shale Gas Research Group (SGRG), Petroleum Research Fund (PRF) (Cost Center-0153AB-A33) and Universiti Teknologi PETRONAS for the financial and technical supports provided to accomplish this research.

Funding The funding was provided by Petroleum Research Fund (Grant 0153AB-A33).

\section{Declarations}

Conflicts of interest The authors declare that they have no known competing financial interests or personal relationships that could have appeared to influence the work reported in this paper.

Open Access This article is licensed under a Creative Commons Attribution 4.0 International License, which permits use, sharing, adaptation, distribution and reproduction in any medium or format, as long as you give appropriate credit to the original author(s) and the source, provide a link to the Creative Commons licence, and indicate if changes were made. The images or other third party material in this article are included in the article's Creative Commons licence, unless indicated otherwise in a credit line to the material. If material is not included in the article's Creative Commons licence and your intended use is not permitted by statutory regulation or exceeds the permitted use, you will need to obtain permission directly from the copyright holder. To view a copy of this licence, visit http://creativecommons.org/licenses/by/4.0/.

\section{References}

Agag T, Akelah A (2011) Polybenzoxazine-clay nanocomposites. In: Ishida H, Agag T (eds) Handbook of benzoxazine resins. Elsevier, Elsevier

Aggrey WN, Asiedu NY, Adenutsi CD, Anumah P (2019) A novel non-ionic surfactant extract derived from chromolaena odarata as shale inhibitor in water based drilling mud. Heliyon 5(5):e01697. https://doi.org/10.1016/j.heliyon.2019.e01697

Ahmed Khan R, Murtaza M, Abdulraheem A, Kamal MS, Mahmoud M (2020) Imidazolium-based ionic liquids as clay swelling inhibitors: mechanism, performance evaluation, and effect of different anions. ACS Omega 5(41):26682-26696. https://doi. org/10.1021/acsomega.0c03560

Akhtarmanesh S, Shahrabi MJA, Atashnezhad A (2013) Improvement of wellbore stability in shale using nanoparticles. J Pet Sci Eng 112:290-295

Al-Arfaj M, Sultan A, Abdulraheem A (2015) Understanding shalefluid interactions using molecular modeling techniques for drilling applications: A literature review

AlMubarak T, AlDajani O, AlMubarak M (2015) A collective clay stabilizers review. In: International Petroleum Technology Conference. OnePetro. https://doi.org/10.2523/IPTC-18394-MS

An Y, Jiang G, Ren Y, Zhang L, Qi Y, Ge Q (2015) An environmental friendly and biodegradable shale inhibitor based on chitosan quaternary ammonium salt. J Pet Sci Eng 135:253-260

Aubry T, Moan M (1997) The rheology of swelling clay dispersions. Rev L'institut Français Du Pétrole 52(2):246-247. https://doi. org/10.2516/ogst: 1997030

Bains AS, Boek ES, Coveney PV, Williams SJ, Akbar MV (2001) Molecular modelling of the mechanism of action of organic clay-swelling inhibitors. Mol Simul 26(2):101-145

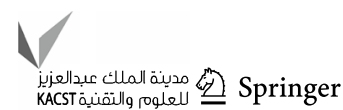


Barati R, Liang J (2014) A review of fracturing fluid systems used for hydraulic fracturing of oil and gas wells. J Appl Polym Sci. https://doi.org/10.1002/app.40735

Berry SL, Boles JL, Brannon HD, Beall BB (2008) Performance evaluation of ionic liquids as a clay stabilizer and shale inhibitor. In: SPE international symposium and exhibition on formation damage control. OnePetro. https://doi.org/10.2118/ 112540-MS

Biswas K, Vasant PM, Vintaned JAG, Watada J (2020) A Review of metaheuristic algorithms for optimizing 3D well-path designs. Arch Comput Methods Eng 28(3):1775-1793

Biswas K, Vasant PM, Vintaned JAG, Watada J (2021) Cellular automata-based multi-objective hybrid grey wolf Optimization and particle swarm optimization algorithm for wellbore trajectory optimization. J Nat Gas Sci Eng 85:103695

Bubalo MC, Radošević K, Redovniković IR, Halambek J, Srček VG (2014) A brief overview of the potential environmental hazards of ionic liquids. Ecotoxicol Environ Saf 99:1-12. https://doi. org/10.1016/j.ecoenv.2013.10.019

Danso DK, Negash BM, Ahmed TY, Yekeen N, Ganat TAO (2020) Recent advances in multifunctional proppant technology and increased well output with micro and nano proppants. J Pet Sci Eng. https://doi.org/10.1016/j.petrol.2020.108026

Danso DK, Negash BM, Yekeen N, Khan JA, Rahman MT, Ibrahim AU (2021) Potential valorization of granitic waste material as microproppant for induced unpropped microfractures in shale. J Gas Sci Eng Nat. https://doi.org/10.1016/j.jngse.2021.104281

de Lara LS, Rigo VA, Miranda CR (2017) Controlling clay swellingshrinkage with inorganic nanoparticles: a molecular dynamics study. J Phys Chem C 121(37):20266-20271

Fujian $\mathrm{Z}$ et al (2019) Integrated hydraulic fracturing techniques to enhance oil recovery from tight rocks. Pet Explor Dev 46(5):1065-1072. https://doi.org/10.1016/S1876-3804(19) 60263-6

Gandossi L (2013) An overview of hydraulic fracturing and other formation stimulation technologies for shale gas production. EUR 26347. Publications Office of the European Union, Luxembourg

Gholami R, Elochukwu H, Fakhari N, Sarmadivaleh M (2018) A review on borehole instability in active shale formations: Interactions, mechanisms and inhibitors. Earth-Sci Rev 177:2-13

Gu M, Mohanty KK (2014) Effect of foam quality on effectiveness of hydraulic fracturing in shales. Int J Rock Mech Min Sci 70:273285. https://doi.org/10.1016/j.ijrmms.2014.05.013

Guancheng J, Yourong Q, Yuxiu A, Xianbin H, Yanjun R (2016) Polyethyleneimine as shale inhibitor in drilling fluid. Appl Clay Sci 127:70-77

Gupta DVS, Hlidek BT (2010) Frac-fluid recycling and water conservation: a case history. SPE Prod Op 25(01):65-69. https:// doi.org/10.2118/119478-PA

Holditch SA, Madani H (2010) Global unconventional gas-it is there, but is it profitable? J Pet Technol 62(12):42-48. https://doi.org/ 10.2118/1210-0042-JPT

Hurnaus T, Plank J (2015) Behavior of titania nanoparticles in crosslinking hydroxypropyl guar used in hydraulic fracturing fluids for oil recovery. Energy Fuels 29(6):3601-3608. https://doi.org/ 10.1021/acs.energyfuels.5b00430

Ismail I, Ann PH (2009) The application of methyl glucoside as shale inhibitor in sodium chloride mud. J Teknol. https://doi.org/10. 11113/jt.v50.175

Jin X et al (2019) Exploration and casting of large scale microscopic pathways for shale using electrodeposition. Appl Energy 247:32-39. https://doi.org/10.1016/j.apenergy.2019.03.197

Joshi SD (1991) Horizontal well technology. United States
Li X et al (2019) Application of gelatin quaternary ammonium salt as an environmentally friendly shale inhibitor for water-based drilling fluids. Energy Fuels 33(9):9342-9350

Liu D et al (2018) Mechanisms for stabilizing and supporting shale fractures with nanoparticles in Pickering emulsion. J Pet Sci Eng 164:103-109. https://doi.org/10.1016/j.petrol.2018.01.048

Lyu Q, Ranjith PG, Long X, Kang Y, Huang M (2015) A review of shale swelling by water adsorption. J Nat Gas Sci Eng 27:1421-1431

Ma J, Yu P, Xia B, An Y, Wang Z (2019) Synthesis of a biodegradable and environmentally friendly shale inhibitor based on chitosan-grafted 1-arginine for wellbore stability and the mechanism study. ACS Appl Bio Mater 2(10):4303-4315. https://doi. org/10.1021/acsabm.9b00566

Miah MI, Elhaj MA, Ahmed S, Hossain ME (2018) Modeling of temperature distribution and oil displacement during thermal recovery in porous media: a critical review. Fuel 226:423-440. https://doi.org/10.1016/j.fuel.2018.04.018

Muhammed NS, Olayiwola T, Elkatatny S, Haq B, Patil S (2021) Insights into the application of surfactants and nanomaterials as shale inhibitors for water-based drilling fluid: a review. J Nat Gas Sci Eng 92:103987

O'Brien DE, Chenevert ME (1973) Stabilizing sensitive shales with inhibited, potassium-based drilling fluids. J Pet Technol 25(09):1089-1110

Patel A, Stamatakis S, Young S, Friedheim J (2007) Advances in inhibitive water-based drilling fluids-can they replace oilbased muds? In: International Symposium on Oilfield Chemistry. OnePetro. https://doi.org/10.2118/106476-MS

Quainoo AK, Negash BM, Bavoh CB, Ganat TO, Tackie-Otoo BN (2020) A perspective on the potential application of bio-inhibitors for shale stabilization during drilling and hydraulic fracturing processes. J Gas Sci Eng Nat. https://doi.org/10.1016/j. jngse.2020.103380

Rahman MT, Negash BM, Moniruzzaman M, Quainoo AK, Bavoh CB, Padmanabhan E (2020) An overview on the potential application of ionic liquids in shale stabilization processes. J Nat Gas Sci Eng 81:103480. https://doi.org/10.1016/j.jngse.2020. 103480

Rahman MT, Negash BM, Moniruzzaman M, Quainoo AK, Bavoh CB, Padmanabhan E (2020) An overview on the potential application of ionic liquids in shale stabilization processes. J Nat Gas Sci Eng. https://doi.org/10.1016/j.jngse.2020.103480

Rahman MT, Negash BM, Idris A, Miah MI, Biswas K (2021) Experimental and COSMO-RS simulation studies on the effects of polyatomic anions on clay swelling. ACS Omega. https://doi. org/10.1021/acsomega.1c03786

Rubbi F, Das L, Habib K, Aslfattahi N, Saidur R, Rahman MT (2021) State-of-the-art review on water-based nanofluids for low temperature solar thermal collector application. Sol Energy Mater Sol Cells 230:111220. https://doi.org/10.1016/j.solmat.2021. 111220

Saleh TA, Ibrahim MA (2019) Advances in functionalized nanoparticles based drilling inhibitors for oil production. Energy Rep 5:1293-1304. https://doi.org/10.1016/j.egyr.2019.06.002

Sehly K, Chiew H-L, Li H, Song A, Leong Y-K, Huang W (2015) Stability and ageing behaviour and the formulation of potassium-based drilling muds. Appl Clay Sci 104:309-317

Uddin F (2018) Montmorillonite: an introduction to properties and utilization. In: Zoveidavianpoor M (ed) Current topics in the utilization of clay in industrial and medical applications. InTech, London

Villada Y, Gallardo F, Erdmann E, Casis N, Olivares L, Estenoz D (2017) Functional characterization on colloidal suspensions containing xanthan gum (XGD) and polyanionic cellulose 
(PAC) used in drilling fluids for a shale formation. Appl Clay Sci 149:59-66. https://doi.org/10.1016/j.clay.2017.08.020

Wang J, Wang S, Lin W, Kang Z, You Q (2017) Formula optimization and rheology study of clean fracturing fluid. J Mol Liq 241:563-569. https://doi.org/10.1016/j.molliq.2017.06.050

Wanniarachchi WAM, Ranjith PG, Perera MSA, Lashin A, Al Arifi N, Li JC (2015) Current opinions on foam-based hydro-fracturing in deep geological reservoirs". Geomech Geophys GeoEnergy Geo-Resour 1(3):121-134

Xiong Z-Q, Li X-D, Fu F, Li Y-N (2019) Performance evaluation of laponite as a mud-making material for drilling fluids. Pet Sci 16(4):890-900. https://doi.org/10.1007/s12182-018-0298-y

Xu J, Qiu Z, Zhao X, Zhong H, Li G, Huang W (2018) Synthesis and characterization of shale stabilizer based on polyethylene glycol grafted nano-silica composite in water-based drilling fluids. J Pet Sci Eng 163:371-377

Xu J, Qiu Z, Zhao X, Zhong H, Huang W (2019) Study of 1-Octyl3-methylimidazolium bromide for inhibiting shale hydration and dispersion. J Pet Sci Eng 177:208-214

Xuan Y, Jiang G, Li Y, Yang L, Zhang X (2015) Biodegradable oligo (poly-L-lysine) as a high-performance hydration inhibitor for shale. RSC Adv 5(103):84947-84958. https://doi.org/10.1039/ C5RA16003K

Yang L et al (2019) Effect of alkyl chain length on shale hydration inhibitive performance of vinylimidazolium-based ionic liquids. Ind Eng Chem Res 58(20):8565-8577

Yekeen N, Padmanabhan E, Idris AK (2018) A review of recent advances in foam-based fracturing fluid application in unconventional reservoirs. J Ind Eng Chem 66:45-71. https://doi.org/ 10.1016/j.jiec.2018.05.039

Yekeen N, Padmanabhan E, Idris AK, Chauhan PS (2019) Nanoparticles applications for hydraulic fracturing of unconventional reservoirs: a comprehensive review of recent advances and prospects. J Pet Sci Eng 178:41-73. https://doi.org/10.1016/j. petrol.2019.02.067

Zhang J, Hu W, Zhang L, Li T, Cai D, Chen G (2019) Investigation of ammonium-lauric salt as shale swelling inhibitor and a mechanism study. Adsorpt Sci Technol 37(1-2):49-60

Zhong H, Qiu Z, Huang W, Cao J (2011) Shale inhibitive properties of polyether diamine in water-based drilling fluid. J Pet Sci Eng 78(2):510-515. https://doi.org/10.1016/j.petrol.2011.06.003 